\title{
Reticular Astrocytes in the Fish Optic Nerve: Macroglia with Epithelial Characteristics Form an Axially Repeated Lacework Pattern, To Which Nodes of Ranvier Are Apposed
}

\author{
Alison Maggs and John Scholes \\ MRC Cell Biophysics Unit, King's College, London, London WC2B 5RL, England
}

\begin{abstract}
Astroglia in lower vertebrate optic nerves are unusual: as shown recently (Giordano et al., 1989; Rungger-Brändle et al., 1989), they express abundant Type II cytokeratin, not glial fibrillary acidic protein (GFAP), the cytoskeletal marker for astrocytes elsewhere. To determine the implications for the glial cells of these epithelial-type cytoskeletons, which are linked up by desmosomal junctions, we analyzed the tissue patterning of fish optic nerve astroglia, which we term reticular astrocytes on account of their uniquely specialized arrangement.
\end{abstract}

The processes of the reticular astrocytes fasciculate extensively with one another in a pattern stabilized by the desmosomes, forming a network laid out in thin planar sheets, or partitions. These are arranged transversely, that is at right angles to the optic fibers and are repeated at regular intervals of about $15 \mu \mathrm{m}$ longitudinally throughout the optic nerve. They merge periodically forming a 3-dimensional framework whose pattern we speculate provides a flexible tissue skeleton for the optic nerve, capable of accommodating eye movements.

Virtually all fibers in mature regions of the optic nerve are myelinated, and we show that nodes of Ranvier mostly occur in register with the partitions, displaying perinodal astrocytic associations resembling those found at CNS nodes in mammals. This clustering may account for the unexpectedly high observed incidence of neighbor pairs of nodes. Among other peculiarities associated with the reticular astrocytic network, one is that up to $20 \%$ of all cells comprise foamy macrophages not found elsewhere in the CNS.

Astrocytes in the optic nerves of amphibia and fish are uniquely specialized, forming a glial territory demarcated from the rest of the CNS by sharp boundaries at the optic nerve head and the optic chiasm (Maggs and Scholes, 1986; Nona et al., 1989). They are exceptional in lacking the astrocyte cytoskeletal marker glial fibrillary acidic protein (GFAP; Dahl and Bignami, 1973; Quitschke et al., 1985; Dahl et al., 1986), and they express instead abundant cytokeratin-type intermediate filaments (IFs), as recently determined immunocytochemically (Markl and Franke, 1988; Rungger-Brändle et al., 1989) and from the DNA

\footnotetext{
Received Aug. 21, 1989; revised Nov. 8, 1989; accepted Nov. 22, 1989.

We thank B. B. Boycott and A. J. Dowding for suggesting improvements to the manuscript.

Correspondence should be addressed to Dr. J. H. Scholes, MRC Cell Biophysics Unit, King's College, London, 26-29 Drury Lane, London WC2B 5RL, England.

Copyright (c) 1990 Society for Neuroscience $0270-6474 / 90 / 051600-15 \$ 02.00 / 0$
}

sequence of the goldfish ON3 glial IF gene (Giordano et al., 1989). They also possess numerous desmosomal junctions (Maturana, 1960; Rungger-Brändle et al., 1989; Fig. 2 below). To explore the implications of this unusual arrangement, we have reexamined the patterning of the astroglia in the optic nerves of cichlid fish, in which we found that they are ordered in a precise and unexpected way.

As a rule, astroglia elsewhere in the CNS in lower vertebrates retain contacts with both pia and ependyma, thus varying widely in appearance in different parts of the CNS (review, Roots, 1986). They express GFAP (Dahl et al., 1986) and partially ensheath endoneurial capillaries (Kruger and Maxwell, 1967; Stensaas and Stensaas, 1968b). They thus possess characteristics intermediate between those of radial glia in the embryo and of the true astrocytes which appear nconatally during terminal gliogenesis in mammals specifically (Ramón y Cajal, 1955; Schmechel and Rakic, 1979a, b; Rakic, 1985).

By contrast, the fish optic nerve glial cells resemble neither radial glia nor astrocytes. Because they are linked up by the desmosomes into a continuous endoneurial network, we propose to call them reticular astrocytes. (We thank A. J. Dowding for suggesting this term.) As will be discussed, they form a specialized mechanical reinforcement for the optic nerve, and other peculiarities are entailed, with general bearing on various aspects of glial organization in the CNS, as follows.

First, optic nerve astrocytes in mammals are heterogeneous, forming 2 distinct populations in situ as well as in primary cultures, one associated with blood vessels and the other dedicated to nodes (Raff, 1989; Miller et al., 1989 a,b). So far, lower vertebrate optic nerve astroglia show no signs of this diversity (Maggs and Scholes, 1986; Miller et al., 1989b; see also below). To clarify the comparative status of the reticular astrocytes, we examined whether they form specific perinodal associations, as found in mammalian white matter (Hildebrand, 1971; Black and Waxman, 1988). In fact, they do. This may also have functional implications, since it results in a clustered spatial distribution of the nodes, with a high incidence of neighbor pairing.

Second, astrocytes in mammals appear while the capillary bed forms (Wolff, 1987) and microglia/macrophages colonize the brain (del Rio-Hortega, 1919, 1920; Skoff et al., 1976; Choi, 1981; Perry et al., 1985). Leukocyte and glial-derived growth factors have recently been identified which may act in a cascade to precipitate this final episode in brain development, when the adult glial framework is formed (Giulian et al., 1988a, b; Richardson et al., 1988; Lillien et al., 1988; Noble, 1988).

In contrast, endoneurial vasculature fails to develop in lower vertebrate optic nerves and the glia share an intriguing motif of 
peculiarities with 2 other cases in which the vasodeficient character of neuroepithelium in the embryo persists in adult life. One of these is the retina, which retains Mullerian radial glia and in which astrocytes differentiate only when retinal blood vessels develop (Schnitzer, 1988a, b). The second is the spinal cord in Agnatha, which is avascular and in which the glia lack GFAP and possess desmosomes (Bertolini, 1964; Mugnaini and Walberg, 1965; Rovainen, 1979; Dahl et al., 1986). Myelin is absent in both these cases, though note the informative exception of the retinal medullary rays (Schnitzer, 1986), and it is also absent or sparse in amphibian optic nerves (Wilson, 1971; Bracho et al., 1975). The fish optic nerve is a unique case where comprehensive myelination occurs in a glial framework lacking the principal marker (GFAP) as well as the morphology and endoneurial vascular connexions characteristic of astrocytes. We report an interesting corollary of this evolutionary experiment, that numerous foamy lipid-laden cells are present in the optic nerve white matter specifically, but not elsewhere in the brain, which had conventional GFAP-positive astroglia (Maggs and Scholes, 1986; Nona et al., 1989).

Finally, cytokeratins are the first of the IF family to appear during vertebrate development, and their expression in lower vertebrate optic nerves could be an indication (cf. RunggerBrändle et al., 1989) that the reticular astrocytes are a persistent immature form. The ribbon-like optic nerve in fish neatly displays the time course of gliodifferentiation during growth, and we made use of this to show that the reticular astrocytes proliferate coordinately with microglia/macrophages and oligodendrocytes, from glioblastic cells in a distinct immature glial framework. This occurs in an abrupt developmental step triggered some time after the arrival of new optic fibers and involves substantial remodeling of the nerve tissue.

\section{Materials and Methods}

Animals. We used mouth-brooding cichlid fish native to the African lakes, belonging to the genus Oreochromis (Trewavas, 1983). These grow well and are easily bred in the laboratory, and originated from stocks in the United Kingdom at the Biology Department, Kingston Polytechnic and the Institute of Aquaculture, Stirling University. The immunofluorescence material presented here came from Oreochromis spilurus and $O$. niloticus, and the electron micrographs from $O$. niloticus, but both species as well as $O$. mossambicus were used for exploratory observations. These fish differ in habits and appearance, but for most purposes, their optic nerves demonstrate a very similar histologic appearance. The lipid-laden cells to be described are especially numerous in the optic nerves of Oreochromine fish, and small species differences were noted in their distribution within the nerve, but these do not affect the observations.

Immunofluorescence microscopy. Two rabbit antisera, raised as previously described (Maggs and Scholes, 1986), were used for indirect immunofluorescence microscopy, in conjunction with Texas red-conjugated donkey anti-rabbit IgG (Amersham International). The primary antisera were directed against optic nerve-specific glial intermediate filament polypeptides eluted from bands separated in SDS-PAGE of optic nerve cytoskeletal preparations. One is specific for a $56 \mathrm{kDa}$ optic nerve glial IF polypeptide as already characterized (anti-band 3: Maggs and Scholes, 1986), and the other was raised against a related $38 \mathrm{kDa}$ band (band 7), which has a similar tissue distribution. These antisera were used interchangeably in pilot studies, giving indistinguishable immunofluorescence patterns in the optic nerve, but anti-band 7 was used for the micrographs presented here.

Optic nerves were either prepared fresh or fixed in $1 \%$ paraformaldehyde in PBS then mounted in Cryo-embed (Bright Instruments) and rapidly frozen. Cryostat sections were cut at circa $10 \mu \mathrm{m}$ and attached to multiwell slides using gelatin-alum subbing. Primary antibodies were applied at 1:200 dilution in PBS containing $2 \%$ BSA and $1 \%$ Triton X100 with azide. Fixed tissue sections were incubated with antibody solutions for up to $24 \mathrm{hr}$ at $4^{\circ} \mathrm{C}$, and unfixed ones for up to $1 \mathrm{hr}$ at

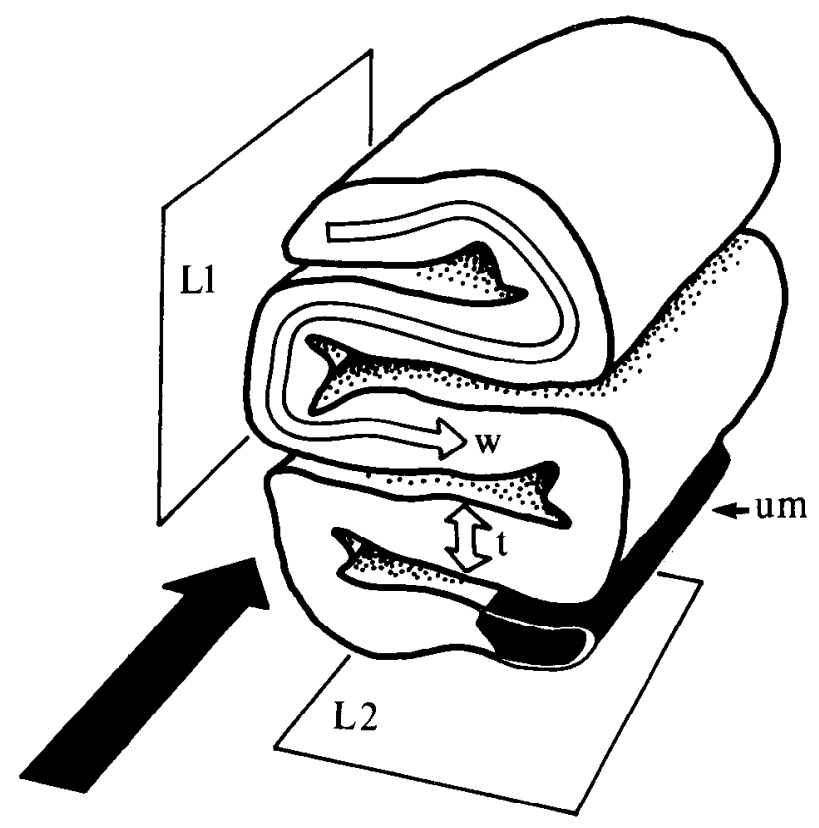

Figure 1. Organization of the ribbon optic nerve in fish. It is a stretch cut from the right optic nerve, viewed in the direction of the brain with the large black arrow indicating the direction of the optic fibers: the $z$-axis. The growing edge of the ribbon, containing new unmyelinated fibers, is placed ventrally and shown in black $(u m)$. The nerve is otherwise fully myelinated. The open arrows indicate the natural $x$ and $y$ coordinates of this structure (Scholes, 1979), namely, the width of the ribbon (w), which is the growth axis, and the orthogonal axis, ribbon thickness $(t)$, which aligns optic axons and glial cells of the same ages and maps retinal sectors. Thesc axcs arc preferentially sampled by the longitudinal section planes $L 1$ and $L 2$.

room temperature. Secondary antibodies were normally preabsorbed using $S M-2$ beads (BioRad) to remove unconjugated fluorochrome, fluorescein isothiocyanate (FITC) or Texas red, which was otherwise sequestered by the lipid-containing cells in the optic nerve. Sections were mounted in glycerol containing phenylene diamine as anti-quench.

Electron microscopy. Optic nerves were exposed by dissection, desheathed and lightly tensioned, and then fixed by immersion in $4 \%$ glutaraldehyde in $150-200 \mathrm{~mm}$ cacodylate buffer at room temperature and $\mathrm{pH} 7.3$ for $0.5-1 \mathrm{hr}$. They were briefly washed (15-30 $\mathrm{min})$ and then postfixed in $1 \%$ OsO4 usually overnight at $4^{\circ} \mathrm{C}$, both in the same buffer. The material was dehydrated in acetone followed by epoxy propane and embedded in Durcupan A/M (EM-scope). Sections were mounted on large slot grids using Pioloform support films (Agar Aids) without carbon coating and stained with uranium and lead salts.

Nodes of Ranvier were counted and measured directly in the electron microscope, since they are sparsely distributed and would have required unworkably large photomontages at the high magnification (up to $70,000 \times$ ) required for reliable identification. The ribbon structure of the optic nerve (illustrated in Fig. 1) enabled systematic searching by scanning a raster, and repeated counts established that errors (mainly of omission) were infrequent.

$S D S-P A G E$. Optic nerves were removed from their sheaths and the ribbons spread out on a glass slide moistened with PBS. Razorblade slices were made under the dissecting microscope to isolate samples, $50-100 \mu \mathrm{m}$ wide, from the growing edge and other age-related positions in the ribbon. The unmyelinated tract at the edge of the ribbon $(\mu \mathrm{m}$ in Fig. 1) has a characteristic transparent appearance contrasting with the opaque white myelin throughout the rest of the nerve, with a clear boundary at which the first slices were made. The age-related ribbon samples were extracted with ice-cold acetone for $5 \mathrm{~min}$, pelleted, and then dissolved by boiling in sample buffer containing $\mathrm{NaDoDSO}_{4}$ and $\beta$-mercaptoethanol, before running on discontinuous gradient gels (Laemmli, 1970). 

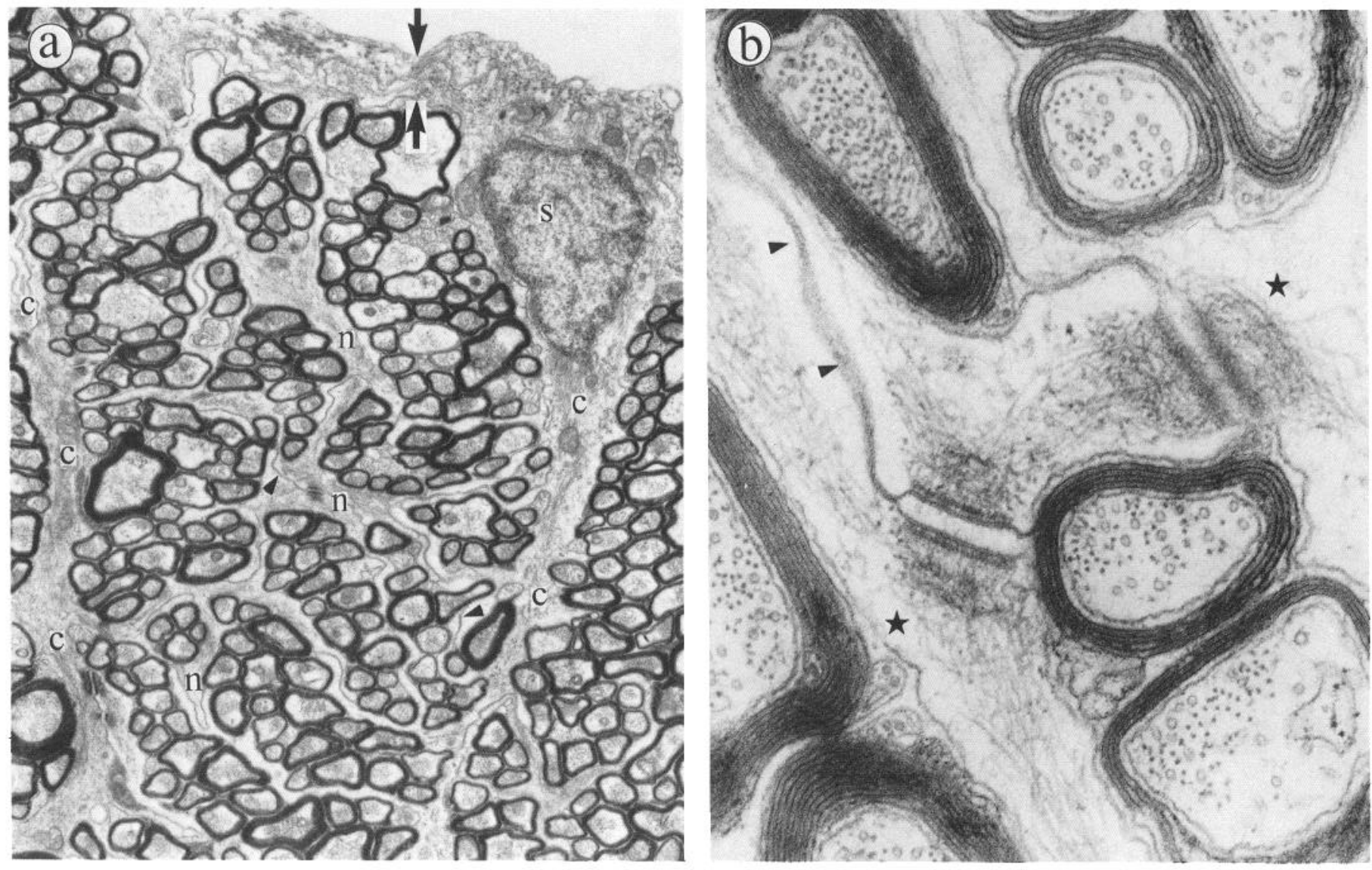

Figure 2. Reticular astrocytes are packed with IFs, their processes fasciculate together and are linked by desmosomes to form a dense endoneurial network. $a$, Transverse EM section showing the glia limitans + rudimentary pia (arrows) and a reticular astrocyte soma ( $s$ ) at the ribbon surface. Major columnar astrocytic processes $(c)$ are joined up by a finer network $(n)$ of processes that fasciculate together (arrowheads) and are joined by desmosomes. $\times 12,110 . b$, Reticular astrocyte desmosomes, showing anchorages of the IF cytoskeleton (arrows). Arrowheads as in $a$. $\times 74,120$.

\section{Results}

The reticular astrocytic network

\section{EM cytology}

The reticular astrocytes form a thin glia limitans superficially and an elaborate network of processes bridging through the ribbon structure of the optic nerve (Fig. $2 a$ ). The cell bodies are located either superficially (as in Fig. $2 a$ ) or endoneurially (see Fig. $3 c$ ) but are otherwise uniform cytologically, and we found no sign that they comprise more than one type, such as occur in mammalian optic nerve (Skoff, 1980; Raff, 1989).

In the intraorbital part of the optic nerve, the ribbon lacks endoneurial blood vessels. The folds are invested by a superficial network of capillaries embedded in the rudimentary pia. However, the glia limitans shows no specialization where it apposes these vessels. Processes of pial cells, as well as collagen fibrils, often separate the capillary basal lamina from the glial end-feet (not shown). Intraorbitally, ribbon folds are only about $100 \mu \mathrm{m}$ thick, but their pattern condenses to pass through the skull foramen, with an increase in thickness. Capillaries are sometimes found endoneurially in this region of the optic nerve, hinting that a thickness threshold exists for vascularization (cf. Schnitzer, 1988b).

The reticular astrocyte processes fasciculate together, showing extensive membrane appositions (arrowheads in Fig. $2 b$, see also Fig. 2a). As in amphibian optic nerves and cyclostome spinal cord, which also lack endoneurial blood vessels (see introductory remarks), they are linked by numerous desmosomes (maculae adhaerentes), positively identified here by their IF anchorages (Fig. $2 b$ ), which form self- and intercellular junctions both in the glia limitans and in the endoneurial glial network. No astrocyte desmosomes were found in the optic tract, where the glia express GFAP (Maggs and Scholes, 1986; Nona et al., 1989), and these structures are not found in the CNS in higher vertebrates (Peters et al., 1976), although Stevenson and Yoon (1982) noted they are present in midbrain ependyma in fish.

As in epithelia, the optic nerve glial desmosomes link the reticular astrocytes into a continuous tissue-wide network, whose unusual pattern will now be described.

\section{Pattern}

Transverse cryostat sections reacted with antiserum specific for optic nerve glial IFs (see Materials and Methods) show columnar cell processes (c, Fig. 3, $a, b$ ) between the glia limitans (arrows) at the 2 surfaces of the ribbon. The columns often include cell somas and are linked together by a fine network of glial processes, with a lacelike reticular appearance (n, Fig. 3, $a, b)$. The sections in Figure 3 are unfixed and detergent-treated (see Materials and Methods), and the immunofluorescence pattern thus represents cytoskeletal IF bundles. The striking anastomosed pattern of the network must result from the desmosomal junctions, and Figure $3 c$ illustrates its characteristic tensed, geodesic 

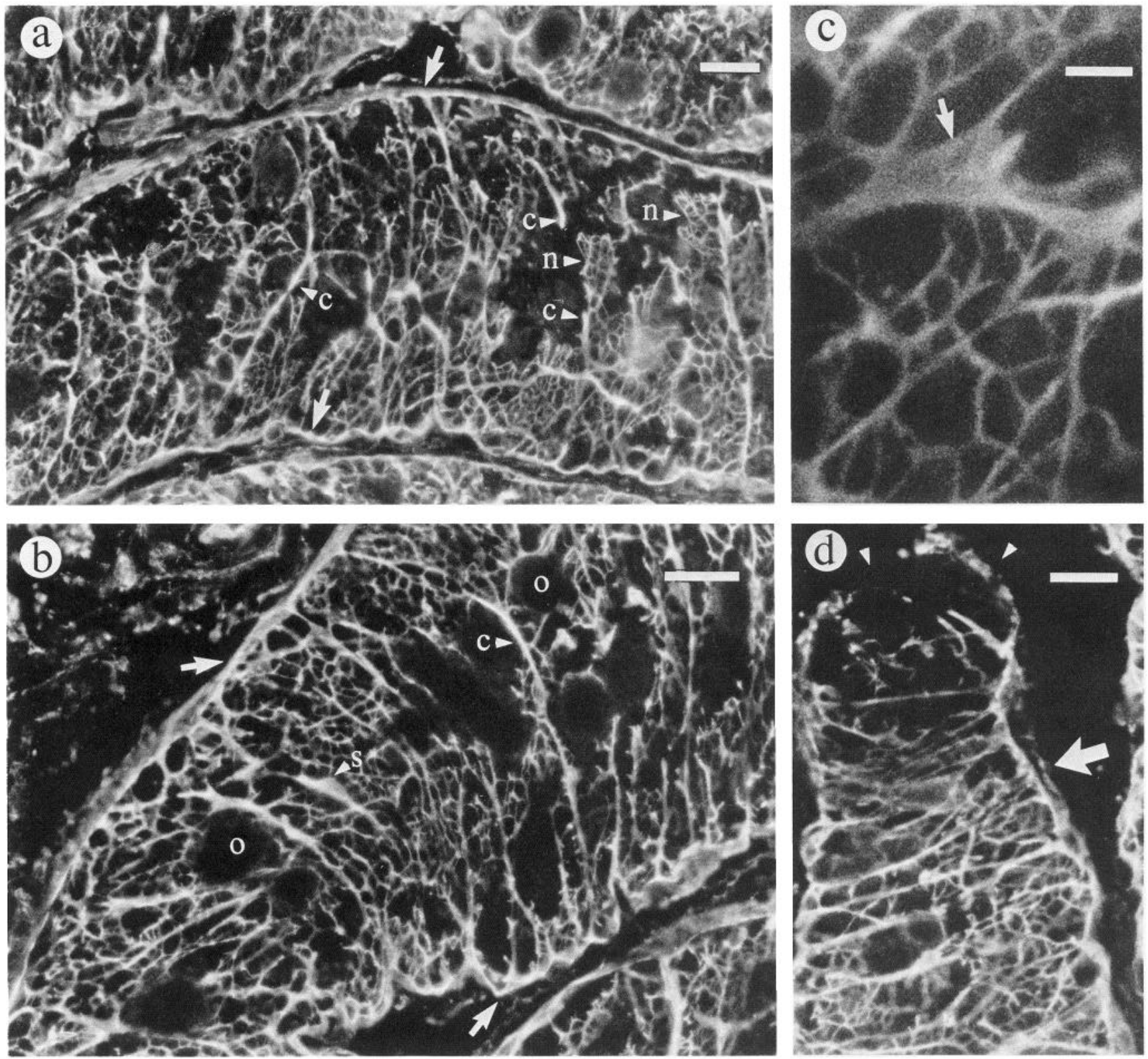

Figure 3. Reticular astrocytes branch finely forming transverse sheets of processes resembling lacework. These immunofluorescence micrographs show the glial cytoskeletons, in unfixed $10 \mu \mathrm{m}$ transverse cryostat sections, reacted with rabbit antiserum against optic nerve glial IF protein (see Methods) $a$, Part of a central fold in the ribbon optic nerve, flanked top and bottom by adjacent folds, showing the glia limitans (arrows) with columnar glial processes $(c)$ supporting areas of more delicate lacelike network $(n)$, which leave the section plane in places, accounting for the irregular gaps. Scale bar, $20 \mu \mathrm{m}$. $b$, Close to the growing edge of the ribbon, the columnar processes $(c)$ are oriented at right angles to the surface glia limitans (arrows). $s$ is an endoneurially placed reticular astrocyte soma, and the circular gaps in the network (e.g., $o$ ) are due to lipid-droplet cells. Scale bar, $20 \mu \mathrm{m}$. $c$, Reticular astrocyte processes and an astrocyte soma (arrow), illustrating the anastomosing structure of the network, which appears to be under tension (see text). Scale bar, $5 \mu \mathrm{m}$. $d$, The extreme growing edge of the ribbon (arrowheads), with the arrow showing where the reticular astrocyte network first appears (cf. Fig. 10). Scale bar, $20 \mu \mathrm{m}$.

appearance. The outlines of individual astrocyte fields are nowhere apparent.

In the sections, the network is punctuated irregularly by vacant spaces, which are of 2 kinds. First, the sheets of lacework intersect the section surfaces (see Fig. $3 a$ ). Second, the nerve contains numerous lipid-laden cells (see Fig. 7 and text), which cause circular gaps in the network (e.g., o, Fig. $3 b$ ). Columnar processes dominate the appearance of the astroglia in the first fold of the ribbon (e.g., Fig. $3 d$, lower left) but become more widely spaced apart by extended areas of network (n) in the older folds of the nerve (Fig. $3 a$ ).
The deceptively irregular patterns of glial processes and spaces seen in transverse sections (Fig. 3) can be interpreted from longitudinal ones (Fig. 4), which show that the glial network is arranged in undulating lace-like sheets, oriented mainly at right angles to the optic fibers. Various examples are shown in Figure $4 b-e$, which are side views of the glial lacework shown in transverse sections in Figure 3. The sheets, which we term partitions, merge periodically (e.g., arrowheads, Fig. $4 c$ ) to enclose an irregular pattern of interpartition spaces. They have a quasi-regular longitudinal spacing of about $15 \mu \mathrm{m}$ (Fig. 4, $b, c$ ), which is roughly uniform throughout the nerve between the eye and the 

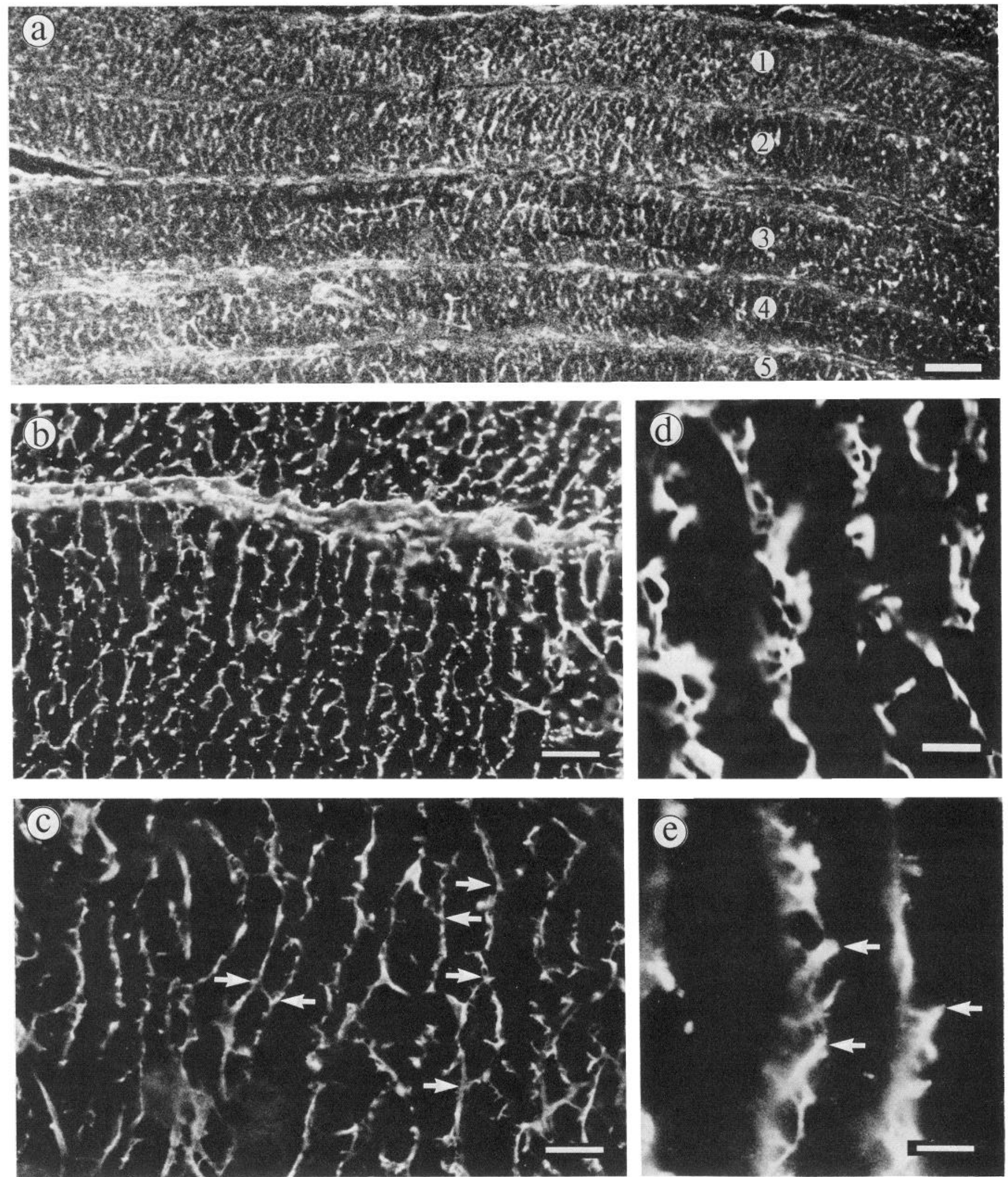

Figure 4. Immunofluorescence micrographs of longitudinal sections of the optic nerve. The lacework sheets of glial processes (shown en face in Fig. 4) are shown here in side view, revealing their quasi-regular longitudinal spacing of around $15 \mu \mathrm{m}$. The optic fibers run from left to right in all cases. Glial IF antibodies and cryostat sections, as in Figure 4. a, This low-magnification micrograph of an unfixed LS (plane L1 in Fig. 1) intersects 5 of the 7 major ribbon folds (numbers), showing that the pattern of the glial network is constant throughout. Scale bar, $75 \mu \mathrm{m}$. $b$, A paraformaldehyde-fixed LS, in which the soluble pool as well as polymerized cytoskeletal IF polypeptides should be preserved, showing a similar pattern to unfixed material. Scale bar, $30 \mu \mathrm{m}$. c, Unfixed LS showing the quasi-regular spacing of the partitions, which merge at intervals (e.g., arrowheads) forming a pattern somewhat like that in a paper garland (plane $L 2$ in Fig. 1). Scale bar, $20 \mu \mathrm{m}$. $d$ and $e$, Higher-magnification views of the glial lacework in partitions, stained at the surfaces of longitudinal cryostat sections. In $e$, the intensity of fluorescence in the major columnar processes (arrowheads) is graded inside the section, giving the impression of depth. Scale bars, 8 and $6 \mu \mathrm{m}$, respectively. 
optic tract, and in newer or older folds of the ribbon (Fig. $4 a$ ). We measured the spacing of partitions in nerves from fish of 3 and $10 \mathrm{~cm}$ standard length which were mounted unfixed and cryosectioned longitudinally in the same block. The nerves were 2 and $6 \mathrm{~mm}$ long, respectively, so growth is approximately allometric, and measurements of average spacing in several different areas were within the SD ( $\pm 4 \%, 5$ areas each) between the 2 nerves. Markham-shifted transparencies (Markham et al., 1964) also clearly revealed equal spacing between nerves over wide areas of the sections. Therefore, partitions must somehow proliferate in number as the optic nerve grows in length throughout the animal's life.

The detergent-treated unfixed sections (Figs. 3 and 4, except part $b$ ) presumably only retained cytoskeletons, not the soluble IF pool, and thus do not necessarily reveal the full extent of the glial network. However, processes of the reticular astrocytes identified either by immunofluorescence in fixed material (Fig. $4 b$ ) or by EM (see Fig. 9) were also aligned in partitionlike arrays, confirming that the network is tightly confined to transverse planes.

In longitudinal sections, the partitions can be viewed in 2 distinct ways. According to the plane chosen, the sections can either intersect the major ribbon folds (plane L1 in Fig. 1) or run parallel to them (plane L2, Fig. 1), thus aligning with the one or other of 2 main axes (width, w, and thickness, $t$, in Fig. 1) of the age-related structure of the optic nerve. While the folded pattern of the ribbon is elaborating during growth in a juvenile fish, cells forming the partition network differentiate in sequence along one of these axes (w in Fig. 1), but in synchrony across the other (thickness, t, in Fig. 1). However, there was no evidence of anisotropy in patterning corresponding with these 2 axes, either at the level of the lacework or in the higher-order pattern of partitions and interpartitions.

To summarize, the reticular astrocytes ramify and link via desmosome contacts, forming a series of transverse sheets of glial processes with a lace-like appearance. These are repeated longitudinally with a regular spacing of about $15 \mu \mathrm{m}$ and merge at intervals to enclose a higher-order pattern of interpartition spaces throughout the nerve.

\section{The arrangement of myelin sheaths}

\section{The oligodendrocyte distribution}

Fish oligodendrocytes are easily recognized in the EM by their dark cytoplasm and microtubule-filled processes which could sometimes be traced to myelin sheaths (Fig. 5a). A sample 155 oligodendrocyte somas in transverse EM sections were all apposed to reticular astrocytes or their major processes, either in the glia limitans or inside the ribbon, suggesting that such contact is the rule. Likewise, oligodendrocyte processes, which connect to widely dispersed myelin sheaths, were mostly found apposed to partitions (cf. Fig. 5a), and infrequently between them.

\section{The arrangement of nodes and internodes}

In mammals, CNS nodes of Ranvier are apposed by perinodal processes from astrocytes (Hildebrand, 1971; Black and Waxman, 1988). Bearing in mind the suggestion that these originate from a special kind of astrocyte (Raff, 1989), we examined whether the reticular astrocytes in the fish form such perinodal complexes.

At least $80 \%$ of nodes are apposed to reticular astrocytes. The cross-sectional appearance of fish nodes is illustrated in Figure

\section{Table 1. Perinodal astrocyte processes}

\begin{tabular}{ll} 
Configuration & $\%$ of cases \\
\hline Touch (e.g., Fig. 5b) & 15 \\
$\leq$ Half (e.g., Fig. 5c) & 40 \\
$>$ Half (e.g., Fig. 5d) & 25 \\
Total & $80 \pm 5.3$ (SD) \\
Vacant nodes & 20
\end{tabular}

Percentage of instances of various configurations of perinodal processes seen in transverse sections. The descriptions indicate how much of the node circumference was invested by processes, and examples are shown in Figure 5, as cited.

$5 b$. Nodes $(\mathrm{N}$, top right) were distinguished from a tiny fraction of unmyelinated axons ( $\mathrm{u}$, bottom left) found throughout the myelinated part of the optic nerve, by their regular outline and subaxolemmal density. Reticular astrocyte processes were found at many but not all nodes. To quantify this, we examined 504 nodes in 7 spaced transverse sections from one optic nerve, logging whether they were apposed by astrocyte processes (recognized by IFs) and classifying the form of the processes as in Table 1 (examples shown in Fig. 5, $b-d$ ). Some $80 \pm 5 \%$ (SD) had processes, most commonly occupying less than half the nodal circumference: no correlation with axon caliber was evident.

This figure has little meaning unless compared with the likelihood of chance associations, which depends on the density of the glial network. To estimate the mark : space ratio of the partition network, we drew straight lines connecting the tips of astrocytic profiles in a longitudinal EM section (Fig. 9) and then measured the areas of the resultant irregular vertical stripes, arriving at a partition/interpartition ratio of 0.22 in this case. From transverse EM sections, the relation between axon diameter and pore size in a partition was such that $68 \%$ of all fibers seen passing through the network were located apposing astrocyte processes. Combining these figures gives $15 \%$ as an upper limit for the frequency of chance appositions, and the observed frequency of $80 \%$ thus represents a strong association.

The $20 \%$ of cases lacking perinodal processes are unlikely to represent sections that sampled bare parts of otherwise occupied nodes since the glial processes normally appose their entire length, as shown in Figure 5e. Also, many of the solitary nodes were located in what appeared to be clear interpartition spaces, where astroglial processes are in any case unlikely to be found (sec Fig. 6).

The longitudinal distribution of the nodes. Most nodes appose partition processes, and must therefore cluster in repeated planes along the optic nerve. Because they occur infrequently, this is not easy to display in longitudinal EM sections, and a better approach might be in thick sections using antibodies directed against nodes (e.g., Schwartz et al., 1981).

The average partition spacing was about $15 \mu \mathrm{m}$, and it is of interest how this compares with the average length of the myelin sheaths. Internode length can be calculated from the frequency of nodes in transverse sections if the nodal length is determined. The small size of the fibers and the density of the astrocytes precluded teasing for direct measurements (see Murray and Blakemore, 1980) of the internodes. We measured node lengths in a longitudinal section of an identified fold of the nerve and found them to be uniformly short $(0.37 \pm 0.08 \mu \mathrm{m}$ averaging the 2 sides; $N=55$ ). The density of nodes was then sampled in 5 nonserial transverse sections (separated by $>10 \mu \mathrm{m}$ ) of the 

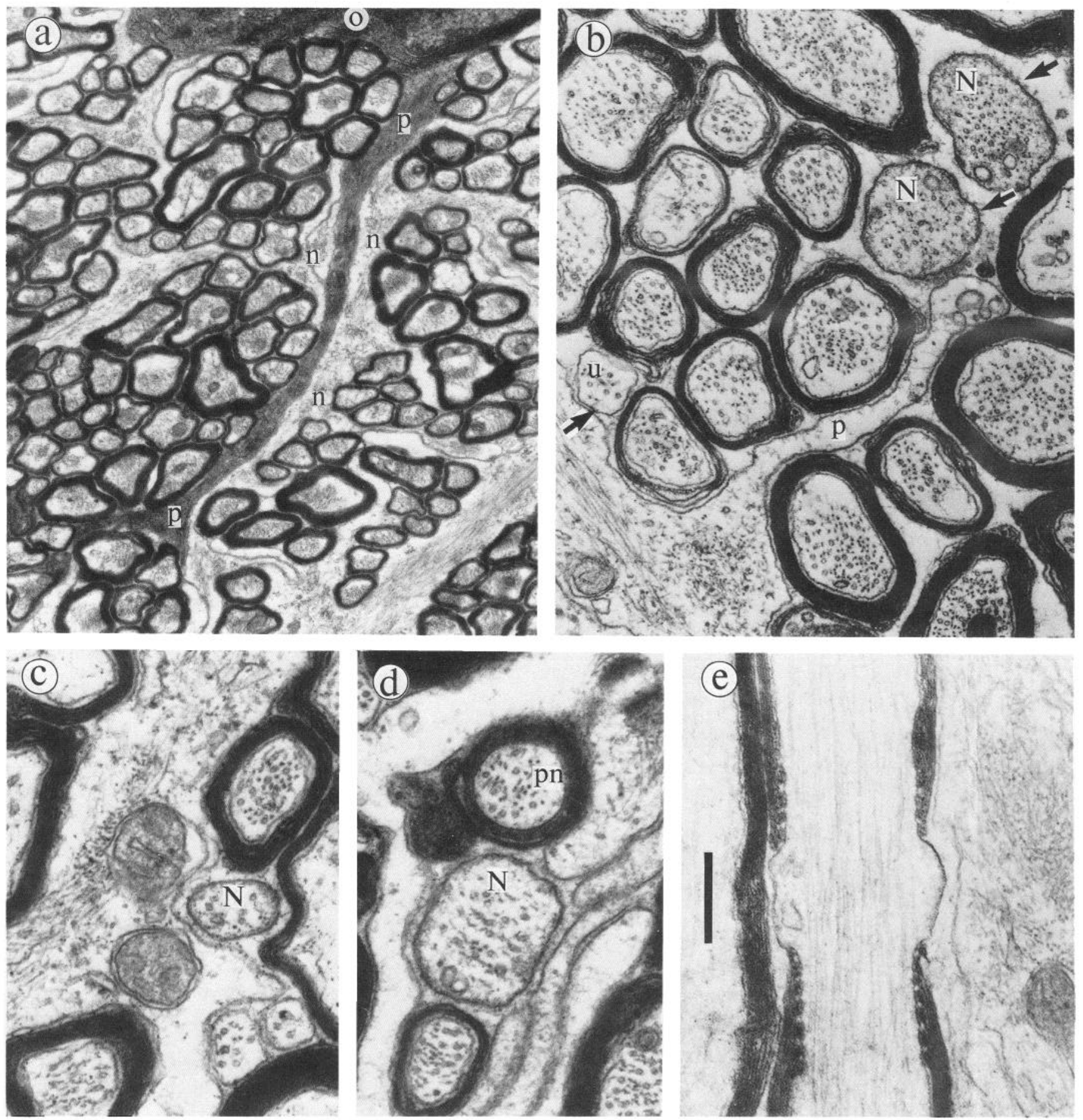

Figure 5. Oligodendrocytes, their processes, and nodes of Ranvier are associated with the reticular astrocyte network. $a$, Transverse EM section, showing an oligodendrocyte $(o)$ and its process $(p)$ running apposed to reticular astrocytic profiles $(n) . \times 16,000$. $b$, Transverse section showing a neighbor pair of nodes $(N$, top right), one touched (Table 1$)$ by a reticular astrocyte process $(p)$. The subaxolemmal density of nodes distinguished them from unmyelinated fibers $(u$, left $) \times 32,000 . c$ and $d$, Examples from the spectrum of perinodal astrocytic processes observed; see Table 1 . $p n$, paranode; other labels as above. $\times 51,000 . e$, Longitudinal section through a representative node, with a reticular astrocyte process to the right. Scale bar, $0.3 \mu \mathrm{m} . \times 51,000$.

same part of this block. Total numbers of axons were estimated by planimetry using several 1000 -fiber samples in each area under consideration. Numbers in the different areas varied between 9000 and 14,500 . Nodes were counted under the electron microscope at a total magnification of $\times 70,000$ by systematically scanning a raster. Errors, as evaluated by repeated scans, were mainly of omission and amounted to less than 5\%. Paranodal profiles were excluded except in glancing instances, when they occupied less than half the circumference of a node. Nodal profiles amounted to $0.0045 \pm 0.0002$ of all fibers in the arrays scanned, and it follows from this that the average internode length is $82 \mu \mathrm{m}$, or 5.5 times the partition spacing of $15 \mu \mathrm{m}$. 
By extrapolation, this small value agrees with direct measurements on larger CNS axons, whose internode lengths are known to be related to fiber diameter. In teased cat spinal cord, Murray and Blakemore (1980) found that $3 \mu \mathrm{m}$ fibers, practically the smallest encountered in their study, have $250 \mu \mathrm{m}$ internodes. Here, fiber diameters were $0.3-4.5 \mu \mathrm{m}$, a range similar to that measured in a very large sample from the optic nerve of the fish Eugerres by Tapp (1974), who determined a fiber diameter mode of $1.0 \mu \mathrm{m}$.

Transverse distribution of nodes. Although nodes are by no means densely distributed in transverse sections, we were struck by the frequency with which neighbor pairs or clusters occur (see Figs. $5 b, 6 a$ ). To evaluate this impression, we used the method devised by Wässle and Riemann (1978) for studies of ganglion cell spacing in the retina. We measured the distribution of nearest-neighbor distances between 307 nodes in 2 montages of part of optic nerve fold 2, for comparison with that expected if they are located at random. The nodes were identified under the electron microscope as above, and for the distance measurements, their locations were marked on low-magnification photomontages prepared beforehand.

This comparison is shown in Figure $6 b$, where the histogram shows the distribution of transverse nearest-neighbor distances between the nodes. Their density, $\lambda$, was calculated from planimetry of the montages, and the spacing of a regular hexagonal lattice at this density is shown by the vertical line. The node density was substituted in Wässle and Riemann's (1978) formula

$$
p(r)=2 \pi \lambda r \exp \left(-\lambda \pi r^{2}\right)
$$

for the probability density, $p(r)$, of nearest-neighbor separation distances, $r$, between locations in a random distribution, to generate the right-hand curve in Figure $6 b$. The left-hand curve is the prediction for a 10 -fold greater nodal density, ie., $10 \times \lambda$.

The observed distribution is markedly different from a random one, and the difference is nicely explained when it is considered that nodes are clustercd in the planes of the partition network. Transverse sections intersect both partition and interpartition domains, in which nodes are distributed differentially, as can be seen in Figure $6 a$. The observed nearest-neighbor distribution is thus a hybrid one, reflecting different in-plane and out-of-plane nodal densities. This analysis shows, then, that one effect of clustering nodes at partitions is to increase significantly the likelihood of neighbor pairing. It will be seen that this principle should operate in any network of perinodal astrocytic processes, patterned or not, and the more strongly so, the sparser the network.

\section{Microglia/macrophages}

In the optic nerves of the African cichlid species studied here, microglia/macrophages (reviewed by Streit et al., 1988; Perry and Gordon, 1988) were unexpectedly numerous, forming up to $30 \%$ of all cells in the myelinated part of the ribbon (Fig. $10 c$ ). They were recognized by standard EM criteria (see Ling, 1981): the most consistent feature was patchy marginated chromatin, and "stringy" ER was present in many cells. They were distinguished from astrocytes by the lack of IFs, and from oligodendrocytes by the absence of the dark, membrane-packed cytoplasm characteristic of these cells. Unclassifiable cells, probably glioblasts, amounted to $4.9 \%$ of the total observed. The microglia included a wide variety of forms, differing in the extent of their cytoplasm and in the spectrum of organelles. About half
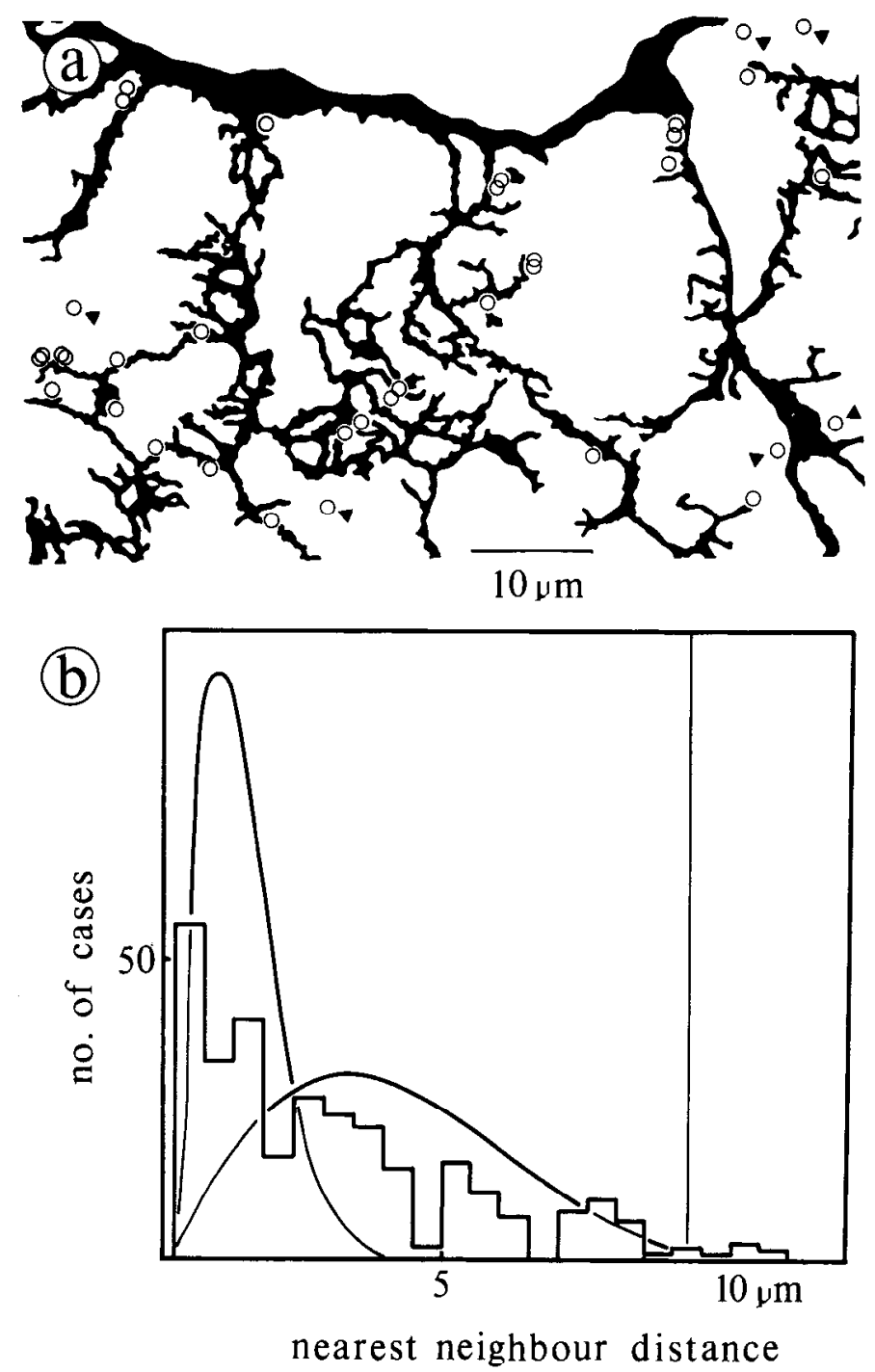

Figure 6. Nodes cluster in the planes of the partitions, resulting in unexpectedly frequent neighbor pairing and grouping. $a$, Tracing showing the location of all nodes and paranodes (circles, much larger than natural size) in a transverse EM section. Black arrowheads indicate solitary nodcs lacking perinodal processes from the reticular astrocytic network (black outlines). Scale bar, $10 \mu \mathrm{m}$. b. Histogram: Observed probability density distribution of nearest-neighbor distances between 307 nodes in transverse EM sections. The right-hand curve is the calculated random distribution for the observed average density of nodes, and the vertical line indicates the spacing that would obtain in a hexagonal lattice at this density. The left-hand curve shows the random distribution for a 10 -fold higher density of nodes. See text.

of them comprised a separate class of uniform large cells heavily laden with lipid droplets and frequently apposed to oligodendrocytes, as shown in Figure 7c. FITC strongly partitions into these cells specifically and is used in Figurc $7 b$ to show their distribution in a longitudinal section through the boundary of the optic nerve and tract. They have the same lengthwise distribution here as the reticular astrocytes (shown for comparison in Fig. 7a), as well as the same age-related distribution at the growing edge of the ribbon (see Fig. $9 c$ ) and are absent elsewhere in the CNS, indicating they are associated with these glia, possibly in a satellite role.

The lipid-filled cells (Fig. 7c) resemble the foamy macrophages that appear transiently in developing CNS fiber tracts in 

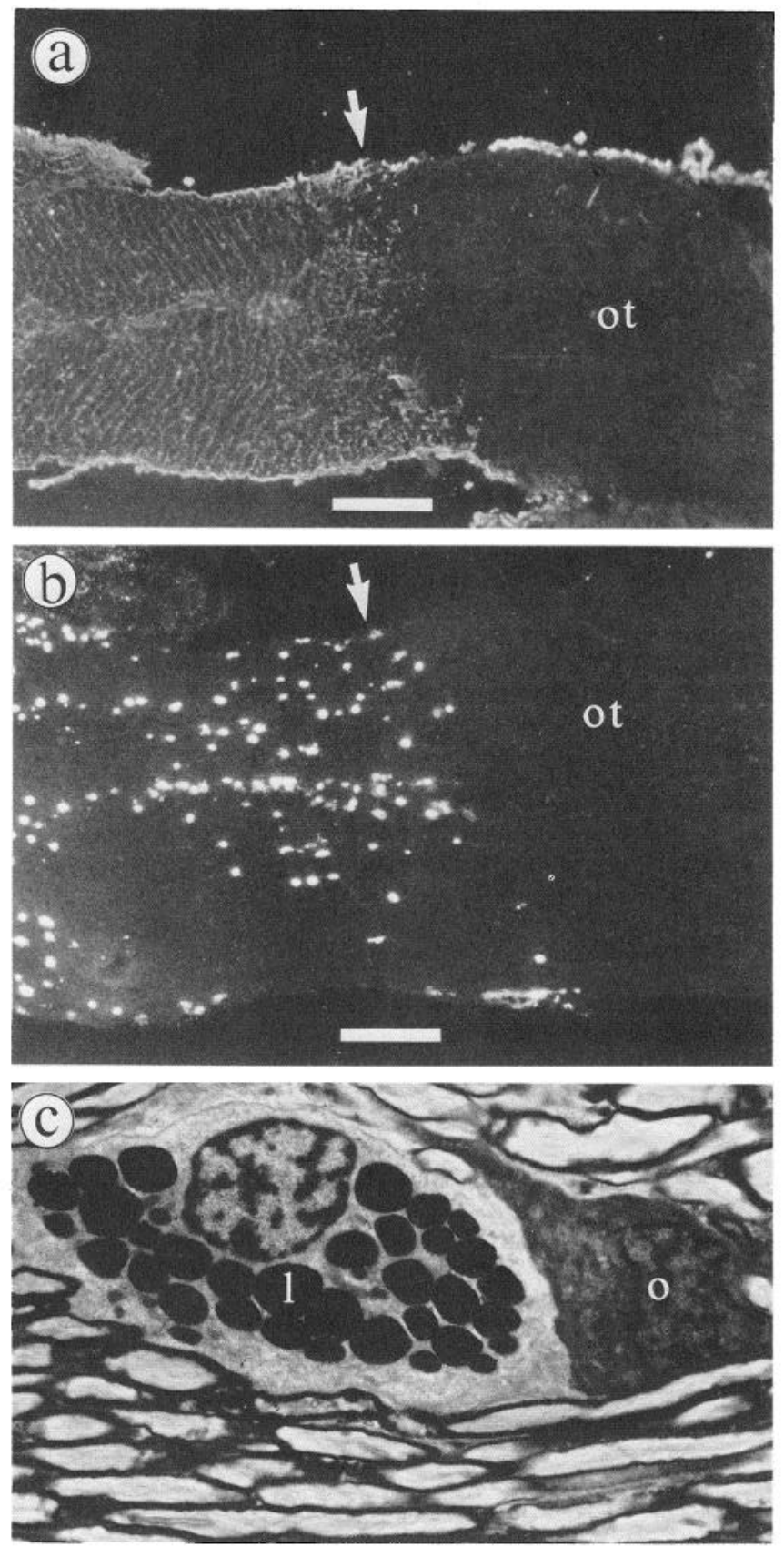

Figure 7. Lipid droplet-filled cells are associated with the reticular astrocyte network in the optic nerve. $a$, An $L S$ through the boundary (arrow) of the optic nerve with the optic tract (ot), showing the regular array of reticular astrocyte partitions (left) with no staining in the tract. Unfixed cryostat section, immunofluorescence for glial IFs as in Figure 4. $b$, Similar $L S$ through the boundary (arrow), with lipid-droplet cells revealed by partitioning free FITC. Scale bar, $100 \mu \mathrm{m}$ (applies also to a). $c$, Near longitudinal electron micrograph showing a lipid-droplet cell $(l)$ apposed to an oligodendrocyte $(o) . \times 2660$.

mammalian neonates (del Rio-Hortega, 1920; Innocenti et al., $1983 a, b)$. Confirmation that they are a special form of macrophage has been obtained using a new monoclonal antibody specific for tissue macrophages in fish (A. J. Dowding, A. Maggs, and J. Scholes, unpublished observations).

\section{Gliogenesis}

During growth in the adult fish, additional optic axons continually grow towards the brain along the new edge of the ribbon optic nerve, which is a glial germinal zone containing progenitor cells and immature glia. The axons are stratified into a chronological record, neatly displaying the time course of gliogenesis. We studied this region to determine whether the immature glia display any pre-pattern for the partitions and how reticular astrocyte differentiation and myelin formation are coordinated.

\section{Immature glia and partitions}

The growing edge of the ribbon contains very large numbers (up to 45,000 ) of small unmyelinated axons queueing up for myelination. They are flanked superficially by glioblasts and immature glial cells, which extend thin processes through the array of fibers. These immature glia contain intermediate filaments (Fig. 8a), and the 56 and $38 \mathrm{kDa}$ IF polypeptides (Maggs and Scholes, 1986) of the mature partition network are present in microdissected samples from this part of the nerve (Fig. $8 b$ ). However, desmosomes are lacking and only appear where the first myelin sheaths differentiate (see below).

Longitudinal EM sections show that the processes of the immature glia are velate in form, often multilaminated, and extend over relatively long distances paraliel to the new unmyelinated axons (Fig. $9 a$ ). This pattern contrasts sharply with the transverse fasciculation (Fig. $2 a$ ) of reticular astrocyte processes among myelinated axons, illustrated in Figure $9 b$. The panel sizes in these tracings were chosen to take account of the larger size of the myelinated fibers, so that both include about the same numbers of axons. The diagram indicates that extensive developmental remodeling of the immature glia is required to generate the adult reticular astrocyte network.

\section{Optic fiber maturation and the time course of gliogenesis}

Figure 10 shows some of the changes in optic nerve fibers and glia that occur coordinately during the transition from immature glia to the reticular astrocyte network. Figure $10 a$ is a tracing from a transverse EM section of the growing edge of the ribbon, showing the appearance of the immature glia [black profiles (i)], and of the reticular glial network at two older locations ( $i i$, iii) to the right. The arrow shows where the first signs of terminal differentiation of the macroglia occur, namely, desmosomes between reticular astrocytes and scattered myelin sheaths belonging to oligodendrocytes. The key to what follows are the vertical contour lines, indicating the density of optic fibers, spaced every 2000 axons. Their spacing widens, midway left to right, where the fibers increase in size as they acquire myelin, and it is evident from the tracings that differentiation of the reticular astrocytes from the immature glia occurs coordinately with this process. The thickness of the ribbon hardly changes at myelin formation (arrow, Fig. 10a). Thus, the entire change in fiber size is accommodated by deforming the array of optic axons past one another along the age axis of the nerve, as indicated by the changing proportions of the areas enclosed by the contour lines in Figure $10 a$.

Figure $10 b$ shows the dynamics of axonal maturation in this region. The abscissal scale is the same as that used in Figure $10 a$, namely, the cumulative number of axons counted in the direction of increasing age (left to right). Circles (left-hand ordinate) show axon diameter, with open and closed symbols representing unmyelinated and myelinated fibers, respectively. 

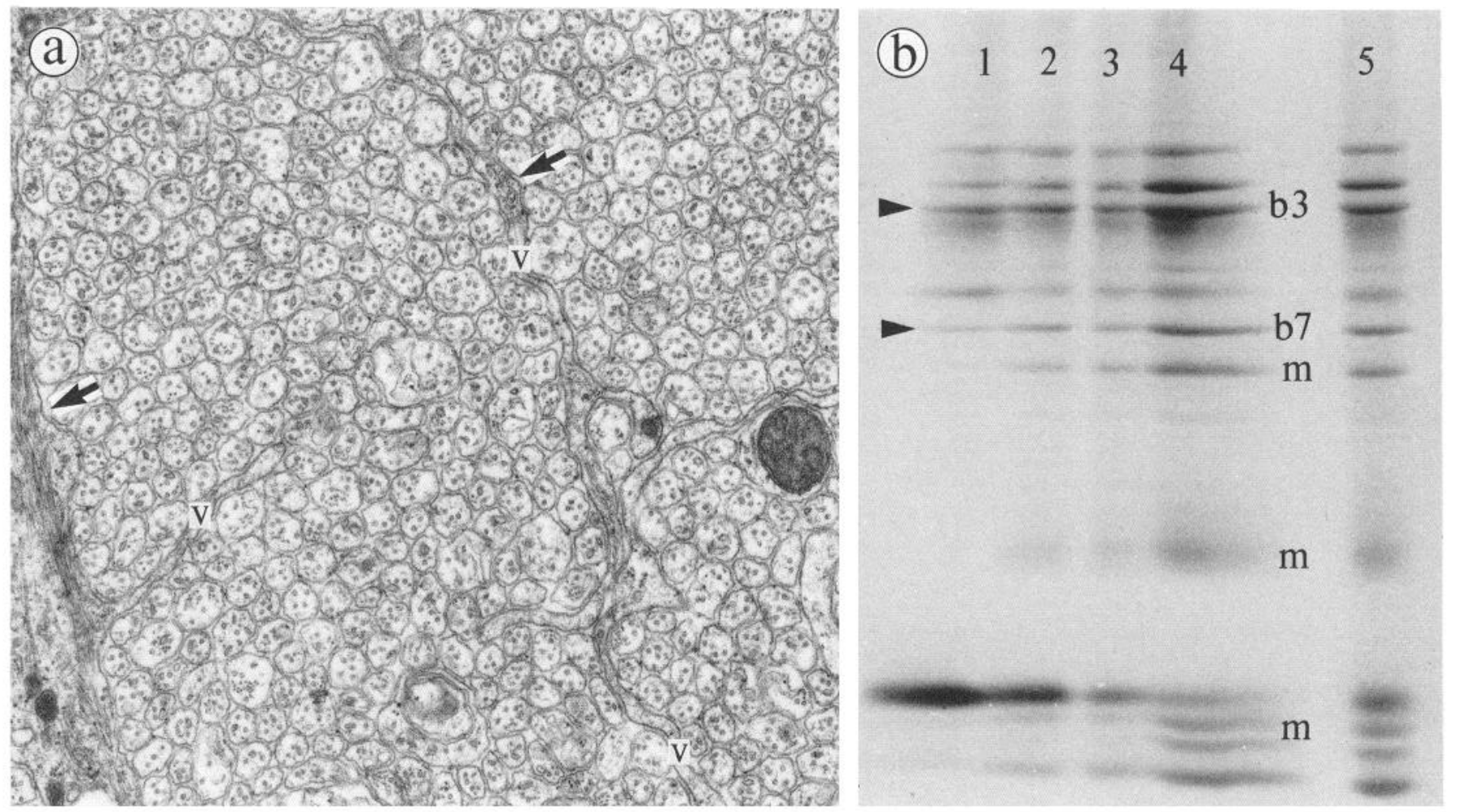

Figure 8. The unmyelinated region at the growing edge of the ribbon (see Fig. 1) contains glial cells with fine velate processes containing IFs composed of the same polypeptides as those in reticular astrocytes. $a$, Transverse EM section showing velate glial processes $(v)$ with IFs (arrows), among numerous fine unmyelinated axons (see also Figs. 9, 10). $b$, SDS-PAGE of samples microdissected from the ribbon at different distances (lanes 1-4) across the growth axis (see Fig. 1): $b 3$ and $b 7$ are the 56 and $38 \mathrm{kDa}$ reticular astrocyte IF bands, respectively, and bands labeled $m$ are myelin-associated proteins. Lane 1 is material from the extreme growing edge of the ribbon (region $i$ in Fig. 10a) lacking myelin but containing abundant glial IF protein $(b 3, b 7)$. Lane 2 is from the immediately adjacent newly myelinated part (region $i i$ in Fig. 10a), showing myelin proteins $(\mathrm{m})$ as well as the glial IFs. Lanes 3 and 4 are from midway, and from the oldest edge of the ribbon respectively, and lane 5 is a sample from an entire optic nerve.

The squares (right-hand scale) show the percentage of myelinated fibers. The abscissal scale is a time axis, showing clearly that axons queue for some time at a constant small size before myelination begins. Once initiated, however, myelin formation proceeds rapidly, completing within a shorter time (the interval 3550,000 axons; abscissa) than spent queueing $(0-35,000)$, with large changes in fiber size. This analysis assumes, of course, that the animal's recent growth (which was rapid) occurred at a constant rate throughout the period of interest. In justification, we have measured similar profiles in many other optic nerves from fish of widely different ages, and there is independent evidence that retinal ganglion cell production in growing fish proceeds linearly with time (Johns, 1977). As a rough guide from our unpublished estimates, 30,000 axons might accumulate in as little as 2 weeks, but growth is completely dependent upon aquarium conditions.

The total number of glial cells of all types per centimeter of axon increases at least 10 -fold during myelination, as shown by the histograms in Figure $10 c$. These represent counts of the different types of glia in 3 regions of the ribbon as indicated, before, during, and after gliogenesis. Cells were counted from $10 \mathrm{EM}$ sections taken at longitudinal intervals of about $10 \mu \mathrm{m}$. Only cell profiles containing nuclei were scored, and the counts were corrected for characteristic longitudinal nuclear size (microglia $<$ macroglia $=5 \mu \mathrm{m}$ ). The numbers of axons in each region were estimated by planimetry of several 1000 fiber samples, making it possible to express the cell counts on a per optic fiber basis. The counts show that there is a sharp increase in cell numbers as the immature glia (that is cells with velate processes and containing IFs; $i$ in Fig. $10 a$ ) are replaced by reticular astrocytes (ii, iii, Fig. $10 a$ ), and that these cells differentiate at the same time as oligodendroglia and myelin appear. The microglia, including the foamy cells, increase in numbers coordinately with macroglial differentiation.

To conclude, reticular astrocytes replace, or differentiate from, the immature glia in a brief episode coordinated with myelin formation. Extensive remodeling and amplification of cell numbers is involved (Figs. 9, 10), much as occurs when astrocytes replace radial glia neonatally in mammals.

\section{Discussion}

We have described a novel pattern formed by the reticular astrocytes in the fish optic nerve, which ramify in regularly repeated transverse planes, the partitions. The main significance of the network pattern is probably to provide a flexible tissue skeleton for the optic nerve, for example, to accommodate eye movements. However, it also determines the spatial distribution of nodes of Ranvier and has unusual associated lipid-laden cells, so there appear to be other functional implications. 


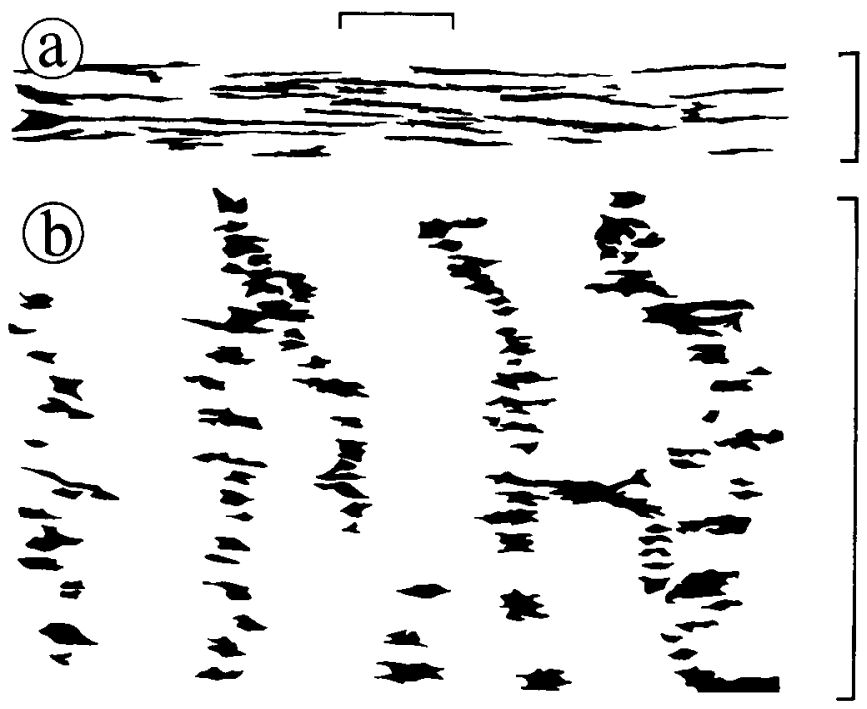

Figure 9. Tracings comparing the arrangement of the velate processes of the immature glia at the growing edge of the ribbon optic nerve with reticular astrocytic processes in longitudinal EM sections: optic fibers run left to right in both cases. Scale bar, $10 \mu \mathrm{m}$. a, Immature glial processes at the growing edge of the ribbon. The panel (vertical bracket) includes about 40 side-by-side unmyelinated fiber profiles. $b, c$, Reticular glial processes in one of the middle folds of the ribbon. Same orientation and scale as $a$, and the vertical bracket represents the same number (40) of (larger) myelinated fiber profiles.

\section{Reinforcing the ontic nerve}

The optic nerve is much tougher than other CNS tissue, e.g., the optic tract, and more resembles peripheral nerve, which is strengthened extracellularly by a matrix of fibrous collagen synthesized by Schwann cells (Bunge et al., 1980). Collagen is not expressed in the CNS, excepting the meninges, and it appears that the optic nerve glia have amplified the cytoskeleton and adopted desmosome linkages in an alternative reinforcing strategy.

The processes of the reticular astrocytes fasciculate together extensively (Fig. 2), so that the arbors of individual glial cells probably overlap widely. Apart from this, our impression from electron microscopy is that the glia resemble an intricately branched form of epidermal prickle cell (see Krstic, 1979). These ramify in flat planes with short desmosome-linked processes enclosing a lacework of spaces at intermediate levels basally in the skin. It scems of grcat interest that a comparable organization attends desmosomes and cytokeratins expressed in the novel context of the optic nerve.

Aside from infrequent partition merges, the glia form a sheetlike meshwork, in which IF bundles linked by desmosomes are woven in all directions transversely through the optic nerve. They are deployed to resist transverse rather than longitudinal forces. This organization presents a striking contrast with the extracellular reinforcement of peripheral nerves, where collagen fibrils are mainly oriented longitudinally to resist stretch.

Why so much emphasis on strengthening the optic nerve in fish, and why transverse rather than axial reinforcement? The eyes are large, almost meeting at the midline in young animals, and the optic nerve contains very large numbers of axons, e.g., 250,000 in $2-3 \mathrm{~cm}$ specimens (unpublished observations). As a result, the thickness of the nerve measures up to $30 \%$ of its length intraorbitally. The optic nerve is loosely suspended in

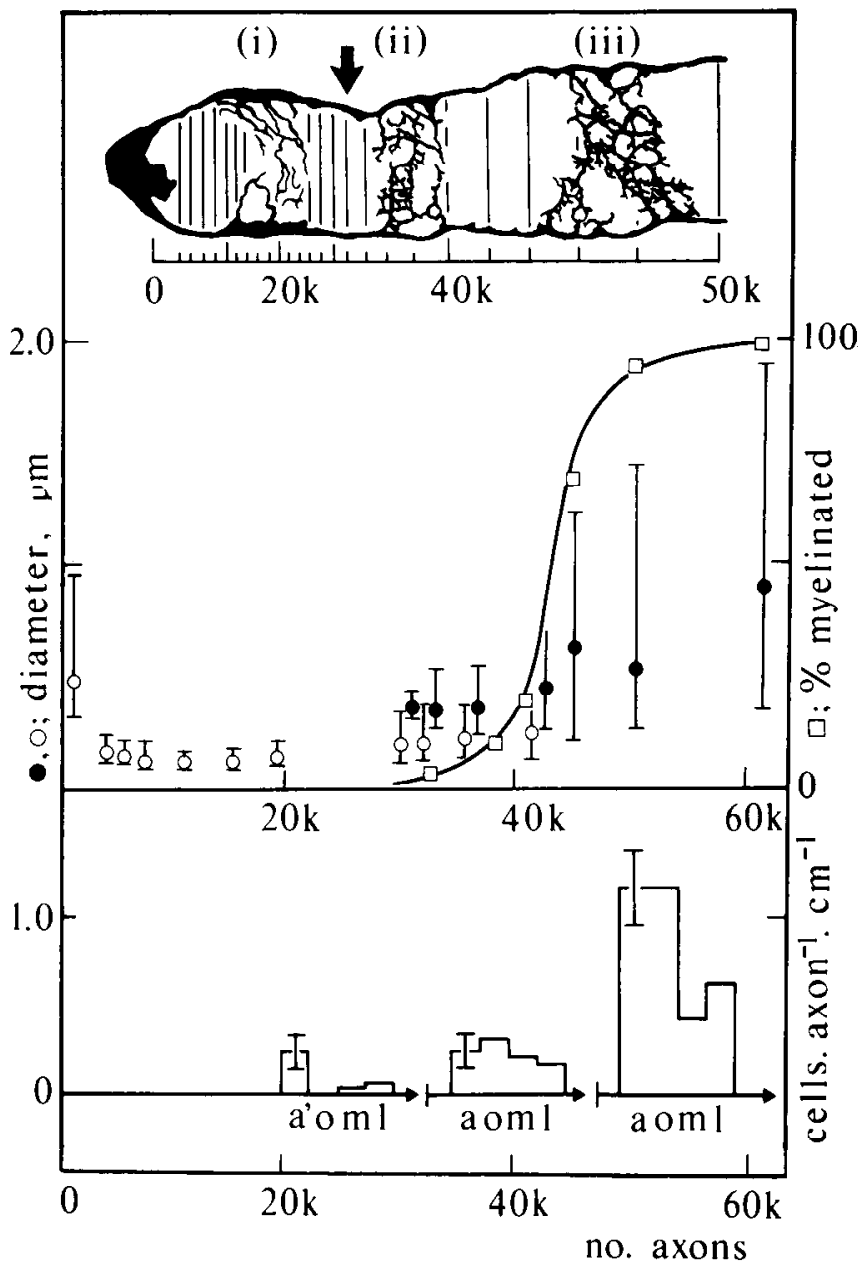

Figure 10. The time course of axonal and glial differentiation displayed at the growing edge of the ribbon optic nerve. $a$, Tracing of a transverse EM section through the growing edge of the ribbon (cf. Fig. 1). A sample area of velate glial processes is shown under $i$ (black outlines), with 2 older samples of reticular astrocytic network, middle and right, beneath $i i$ and $i i i$. The vertical lines are contours, each enclosing approximately 2000 axons, as indicated by the (nonlinear) scale below $(50 \mathrm{k}=50,000$ axons), and myelin formation begins at the arrow (see text). $b$, The time course of axonal maturation. Fiber diameter changes and myelin formation at the new edge of the ribbon are shown on a time scale (abscissa) represented in units of axons numbers, counted in the direction of increasing age, i.e., left to right in $a$ (see also Fig. 1). This makes the assumption that recent growth occurred at a constant rate (see text). Circles represent fiber diameter (left-hand scale): open symbols indicate unmyelinated axons, with the large value at the extreme left due to sampling growth cones, while filled symbols are myelinated fibers. Vertical bars are the ranges of these measurements. Squares and curve show the percentage of myelinated fibers (right-hand scale; see text). $c$, The histograms show glial cell densities [cells per axon per $\mathrm{cm}$ (scale to the left)] calculated from counts in repeated EM sections (see text) in 3 successive age-related regions of the ribbon. The regions were chosen to include cell populations before, during, and after gliodifferentiation, and their extent is indicated by the horizontal arrows referring to the abscissa, which is the same scale of axon numbers as in $b$, enabling comparison with the diagram in $a$. Vertical bars are representative standard deviations. $a$, immature astrocytes; $a$, reticular astrocytes; $o$, oligodendrocytes; $m$, microglia; $l$, lipid-droplet cells.

the orbit, so that normal eye movements probably do not impose overall stretch so much as shearing and fraying forces within the optic fiber array. We suggest that the transverse organization of the glial IFs is a design for resisting stresses of this kind. Oligodendrocytes characteristically connect with their myelin 
sheaths via long and very thin processes, which generally run transversely through fiber tracts (see Fig. $5 a$ and also Stensaas and Stensaas, 1968a). These may be especially vulnerable to shearing, and it may be significant that they run embedded in the partition network for the most part (Fig. 5a).

Desmosomes are very rarely found in the vertebrate CNS, principally in lower vertebrate optic nerves and Agnathan brains, (see introductory remarks). Their importance here is to link the cytoskeletons (Overton, 1977; Garrod, 1986) of the glial cells into a continuous tissue-wide reinforcing meshwork, as provided by extracellular matrix in the PNS. This is in complete contrast with the arrangement of astroglia elsewhere in the vertebrate CNS, where adherent junctions (almost always zonulae, not desmosomes; although see Stevenson and Yoon, 1982) are confined strictly to the pial and ependymal surfaces of the brain (Peters et al., 1976). So far as is known, the endoneurial arbors of astrocytes lack any intercellular cytoskeletal linkages, although they are coupled electrically into a syncytium.

The IF cytoskeletons in the reticular astrocytes are most likely composed of cytokeratins, to judge from the presence of desmosomes and the recent identification of Type II keratins in fish (Markl and Franke, 1988; Giordano et al., 1989) and amphibian (Rungger-Brändle et al., 1989) optic nerves. We originally proposed that the major $(56 \mathrm{kDa})$ cichlid optic nerve glial IF protein is vimentin-like (cf. Jones et al., 1986; Maggs and Scholes, 1986; Quitschke and Schechter, 1986), mainly on grounds of its distribution in mesodermal tissues, e.g., vascular endothelium, which characteristically express vimentin in other vertebrates. However, Markl and Franke (1988) have since shown that fish vascular endothelial cells are exceptional in expressing cytokeratins. There is evidence that desmosomes can anchor vimentin-containing IFs (Kartenbeck et al., 1983, 1984), but they are normally cytokeratin-associated structures, and it is known that fish are unusual in that various mesothelial tissues, including vascular endothelium, have desmosomes (Whitear et al., 1980).

It is of major interest, of course, whether patterns in the tissue distribution of cytoskeletal proteins and junctions reflect underlying developmental or evolutionary restrictions, or represent case-by-case tissue-mechanical requirements. Here, the optic nerve desmosomes could be viewed as reflecting the ancient ectodermal origins of the CNS (see Rungger-Brändle et al., 1989) or as an adaptation for special stresses in the orbit. Various studies (see, for example, Kartenbeck et al., 1983; Mattcy and Garrod, 1985; Jahn et al., 1987; Ferretti et al., 1989; Kasper et al., 1988; Owaribe et al., 1988) have found significant exceptions to the consensus tissue-specific distributions of the major classes of IFs and adherent junctions.

\section{Partitions and nodes}

Distributing astrocytic processes and nodes in transverse planes could be an economical arrangement for some of the proposed functions of the astroglial syncytium, e.g., buffering the extracellular space (Kuffler et al., 1966; Orkand et al., 1966; Newman, $1986,1987,1988)$. Tortuosity of the glial cytoplasmic pool is less than in the case of a diffuse pattern. Moreover, since cells, as opposed to extracellular space, are a significant route for electrical current flow in CNS tissue (Gardner-Medwin, 1983), it is possible that the arrangement of the partitions has implications for current fields surrounding activc nodes.

Some $80 \%$ of nodes were apposed to processes of the reticular astrocyte network (Fig. 6, Table 1), indicating a strong associ- ation since we calculated that chance appositions, in the case of an independent distribution, should amount to only $15 \%$. However, $20 \%$ of nodes lacked perinodal processes: one possible reason for this is that the optic nerve in fish is a plastic structure. It grows continually in length (up to several partition spacings per day; unpublished estimates), and vacant nodes could arise transiently in this process.

Newly discovered active glial membrane responses to propagated impulses, as well as to neurotransmitters (Marrero et al., 1989; Usowicz et al., 1989), suggest a more pivotal role for the association between nodes and astrocytes than there has so far been grounds to suspect. How does the perinodal association here compare with that in mammals, where very elaborate coronas of astrocytic processes have been described? Despite much speculative interest in their possible functions (reviewed by Black and Waxman, 1988), mammalian nodal processes have never been surveyed quantitatively, and the most impressive descriptions concern large fibers $(<5 \mu \mathrm{m}$ diameter). The glial investment of nodes belonging to small fibers in mammals $(<1 \mu \mathrm{m})$ is described as much simpler or absent (Hildebrand, 1971) and is thus probably comparable to that in the fish optic nerve (Table 1).

Partitions may be unique to the elaborate optic nerves of cichlid fish: there are so far no hints of such structures elsewhere. Necturus optic nerve neuroglia have similar cytology (Bracho et al., 1975), but the nerve lacks myelin, and neuroglial processes radiate diffusely (Tang et al., 1985). In rat optic nerve, which is fully myelinated, astrocytes comprise 2 morphological variants expressing different markers (Raff, 1989; Miller et al., 1989b; see introductory remarks). Both of them, particularly the longitudinally ramified type reported to contact nodes (Miller et al., 1989a), which resembles the classical white matter astrocyte (Cajál, 1955), have diffuse fields unlikely to impose any pattern on the spatial distribution of the nodes. It should be stressed that apart from their association with nodes, reticular astrocytes lack any noteworthy resemblance to the nodal, or Type 2, astrocytes described in mammalian optic nerve.

\section{Gliogenesis in the optic nerve}

We found that the axial spacing of the partitions and the general appearance of the network is the same between ribbon folds and in optic nerves of widely different lengths from fish of different sizes. This would result if the partition spacing reflects some invariant cell packing factor, for example, the size of the astrocytic end-feet in the glia limitans. Growth must therefore occur by addition of more cells, but in what distribution is unclear.

Nodes and perinodal processes appear together during development, which has raised the question whether their interaction are a factor determining the spacing of nodes (see Hildebrand and Waxman, 1984; reviewed by Black and Waxman, 1988). In this case, however, we found that partition spacing is only a fraction (18\%) of the estimated average internode length in mature fish optic nerve fibers. We looked for signs of partition prepatterning in the immature glial cells at the growing edge of the optic nerve, but found none. Figure 10 shows that processes of these cells extend longitudinally, typically enabling axonal contacts stretching at least $30 \mu \mathrm{m}$ axially, that is, nearly 100 times the longitudinal contact possible at nodes once myelin has formed.

Figures 9 and 10 show the abrupt changes in the numbers and pattern of all types of neuroglia that accompany myelin formation: the reticular astrocytes cannot be considered an im- 
mature glial form. A spectacular remodelling of the optic nerve at gliogenesis is concealed by the near-constant thickness of the ribbon, which prevails despite of a 10-fold increase in the crosssectional area occupied by individual optic axons. As indicated by the changes in the proportions of fiber number contours in Figure $10 a$, axons must be redistributed past one another transversely in the direction of the growth axis. It is possible that these movements interact with or somehow contribute to the emergent patterning of the partitions. Reticular astrocyte processes bridge between the 2 surfaces of the ribbon where myelin is formed (Figs. $3 d, 10 a$ ): they must be the structural element maintaining the near-constant thickness of the tissue during this episode. Their mechanical properties can thus be seen as a major factor underlying morphogenesis of the characteristic ribbon shape of the fish optic nerve.

Macrophages/microglia are unusually numerous in the fish optic nerve, comprising up to $30 \%$ of all cells in the myelinated part of the ribbon (see Fig. 10c, m, 1). Much as in mammalian CNS (Vaughn, 1969; Privat, 1975; Imamoto and Leblond, 1978; Imamoto et al., 1978), the microglia become numerous at the same time that oligodendrocytes and reticular astrocytes appear in the ribbon (Fig. 10c). By contrast, in Necturus optic nerve, where no myelin is formed, microglia are reportedly absent (Bracho et al., 1975).

In the African cichlids used in this study about half the microglia in the optic nerve comprise foamy cells, resembling Gitterzellen, which appear in a transient manifestation first described as encephalitis neonatorum (Virchow, 1867; Eichhorst, 1875; del Rio-Hortega, 1920) in normal developing CNS fiber tracts in mammalian neonates. These cells are confined to the myelinated part of the nerve, and their longitudinal distribution is coextensive with that of the reticular astrocytes (Figs. 7, 10c). They cannot be associated with axonal pruning, as often suggested in the case of Gitter cells in fetal mammalian CNS (Innocenti et al., 1983a, b; Perry and Gordon, 1988). Instead, we speculate that they may reflect some deficiency of normal astroglial functioning in lipid transport (see Boyles et al., 1985; Pitas et al., 1987). This might be seen as a penalty attached to the high mechanical specialization and sparse vascular connections of the reticular astrocyte network.

\section{References}

Bertolini B (1964) Ultrastructure of the spinal cord of the lamprey. J Ultrastruct Res 11:1-24.

Black JA, Waxman SG (1988) The perinodal astrocyte. Glia 1:169183.

Boyles JK, Pitas RE, Wilson E, Mahley RW, Taylor JM (1985) Apolipoprotein-E associated with astrocytic glia of the central nervous system and with non-myelinating glia of the PNS. J Clin Invest 76: $1501-1513$.

Bracho H, Orkand PM, Orkand RK (1975) A further study of the fine structure and membrane properties of neuroglia in the optic nerve of Xenopus. J Neurobiol 6:395-410.

Bunge MB, Williams AK, Wood PM, Uitto J, Jeffrey JJ (1980) Comparison of nerve cell and nerve cell plus Schwann cell cultures, with particular emphasis on basal lamina and collagen formation. J Cell Biol 84:184-202.

Choi BH (1981) Haematogenous cells in the central nervous system of developing human embryos and fetuses. J Comp Neurol 196:683694.

Dahl D, Bignami E (1973) Immunochemical and immunofluorescence studies of the glial fibrillary acidic protein in vertebrates. Brain Res 61:279-293.

Dahl D, Crosby CJ, Sethi JS, Bignami E (1986) Glial fibrillary acidic (GFA) protein in vertebrates: Immunofluorescence and immunoblotting study with monoclonal and polyclonal antibodies. J Comp. Neurol 239:75-88. del Río-Hortega P (1919) El "tercer elemento" de los centros nerviosos. Bol Soc Esp Biol 9:69-120.

del Rio-Hortega P (1920) La microglia y su transformación en celulas en bastoncito y cuerpos gránulo-adiposus. Trab Lab Invest Biol Madrid 18:37-82

Eichhorst H (1875) Über die Entwicklung des menschlichen Ruckenmarkes und seiner Formelemente. Virchow's Arch Pathol Anat 64: 425-475.

Ferretti P, Fekete DM, Patterson M, Lane EB (1989) Transient expression of simple epithelial keratins by mesenchymal cells of regenerating newt limb. Dev Biol 133:415-424.

ffrench-Constant C, and Raff MC (1986) The oligodendrocyte-type 2astrocyte lineage is specialised for myelination. Nature 323:335-338.

Gardner-Medwin AR (1983) Analysis of potassium dynamics in mammalian brain tissue. J Physiol (Lond) 335:393-426.

Garrod DR (1986) Desmosomes, cell adhesion molecules and the adhesive properties of cells in tissues. J Cell Sci Suppl 4:221-237.

Giordano S, Glasgow E, Tesser P, and Schechter N (1989) A Type II keratin is expressed in glial cells of the goldfish visual pathway. Neuron 2:1507-1516.

Giulian D, Young DG, Woodward J, Brown DC, and Lachmann LB (1988a) Intcrleukin-1 is an astroglial growth factor in the developing brain. J Neurosci 8:709-714

Giulian D, Woodward J, Young DG, Krebs JF, Lachman LB (1988b) Interleukin-1 injected into mammalian brains stimulates astrogliosis and neo-vascularization. J Neurosci 8:2485-2490.

Hildebrand C (1971) Ultrastructural and light microscopic studies of the developing feline spinal cord white matter. I. The nodes of Ranvier. Acta Physiol Scand Suppl 364:81-108.

Hildebrand C, Waxman SG (1984) Postnatal differentiation of rat optic nerve fibres: electron microscopic observations on the development of nodes of Ranvier and axoglial relations. J Comp Neurol $224: 25-37$

Imamoto K, Leblond CP (1978) Radioautographic investigation of gliogenesis in the corpus callosum of young rats: II. Origin of microglial cells. J Comp. Neurol 180:130-164.

Imamoto K, Paterson J, Leblond CP (1978) Radioautographic investigation of gliogenesis in the corpus callosum of young rats: I. Sequential changes in oligodendrocytes. J Comp Neurol 180:115-138.

Innocenti GM, Clarke S, Koppel H (1983a) Transitory macrophages in the white matter of the developing visual cortex: I. Light and electron microscopic characteristics and distribution. Dev Brain Res $11: 39-54$.

Innocenti GM, Clarke S, Koppel H (1983b) Transitory macrophages in the white matter of the developing visual cortex: II. Development and relations with axonal pathways. Dev Brain Res 11:55-66.

Jahn L, Fouquet B, Rohe K, Franke WW (1987) Cytokeratins in certain endothelial and smooth muscle cells of two taxonomically distant vertebrate species, Xenopus laevis and man. Differentiation $36: 234-254$

Johns PR (1977) Growth of the adult goldfish eye. III. Source of the new cells. J Comp Neurol. 176:343-358.

Jones PS, Tesser P, Keyser KT, Quitschke W, Samadi R, Karten HJ, Schechter N (1986) Immunohistochemical localisation of intermediate filament proteins of neuronal and non-neuronal origin in the goldfish optic nerve: specific molecular markers for optic nerve structures. J Neurochem 47:1226-1234.

Kartenbeck J, Schmid E, Franke WW, Geiger B (1983) Specific attachment of desmin filaments to desmosomal plaques in cardiac myocytes. EMBO J 2:735-742.

Kartenbeck J, Schwechheimer K, Moll R, Franke WW (1984) Attachment of vimentin filaments to desmosomal plaques in human meningiomal cells and arachnoid tissue. J Cell Biol 98:1072-1081.

Kasper M, Moll R, Stosiek P (1988) Distribution of intermediate filaments in human umbilical cord: unusual triple expression of cytokeratins, vimentin and desmin. Zool Jb Anat 117:227-233.

Krstic RV (1979) Ultrastructure of the mammalian cell: an atlas. Berlin: Springer Verlag.

Krüger L, Maxwell DS (1967) Comparative fine structure of vertebrate neuroglia: teleosts and reptiles. J Comp Neurol 129:115-142.

Kuffler SW, Nicholls JG, Orkand RK (1966) Physiological properties of glial cells in the central nervous system. J Neurophysiol 36:768786 .

Laemmli UK (1970) Cleavage of structural proteins during the assembly of the head of bacteriophage T4. Nature 227:680-685.

Lillien LE, Sendtner M, Rohrer H, Hughes SM, Raff MC (1988) Type- 
2 astrocyte development in rat brain cultures is initiated by a CNTFlike protein produced by Type-1 astrocytes. Neuron 1:485-494.

Ling EA (1981) The origin and nature of microglia. Adv Cell Neurobiol 2:33-82.

Maggs A, Scholes J (1986) Glial domains and nerve fibre patterns in the fish retinotectal pathway. J Neurosci 6:424-438.

Markham R., Frey S, Hills GJ (1964) Methods for enhancement of image detail and accentuation of structure in electron microscopy. Virology 20:88-102.

Markl J, Franke WW (1988) Localisation of cytokeratins in tissues of the rainbow trout: fundamental differences in expression pattern between fish and higher vertebrates. Differentiation 39:97-122.

Marrero H, Astion ML, Coles JA, Orkand RK (1989) Facilitation of voltage-gated ion channels in frog neuroglia by nerve impulses. Nature 339:378-380.

Mattey DL, Garrod DR (1985) Mutual desmosome formation between all binary combinations of human, bovine, canine, avian and amphibian cells: desmosome formation is not tissue or species specific. J Cell Sci 75:377-399.

Maturana H (1960) The fine anatomy of the optic nerve of Anuransan electron microscope study. J Biophys Biochem Cytol 7:107-119.

Miller RH, Fulton BP, Raff MC (1989a) A novel type of glial cell associated with nodes of Ranvier in the rat optic nerve. Eur. J Neurosci 1:172-180.

Miller RH, ffrench-Constant C, Raff MC (1989b) The macroglial cells of the rat optic nerve. Annu Rev Neurosci 12:517-534.

Mugnaini E, Walberg F (1965) The fine structure of the capillaries and their surroundings in the cerebral hemispheres of Myxine glutinosa. Z Zellforsch 66:333-351.

Murray JA, Blakemore WF (1980) The relation between internodal length and fibre diameter in the spinal cord of the cat. J Neurol Sci 45:29-41.

Newman EA (1986) High potassium conductance in astrocyte endfeet. Science 233:453-454

Newman EA (1987) Distribution of potassium conductance in mammalian Muller (glial) cells: a comparative study. J Neurosci 7:24232432.

Newman EA (1988) Potassium conductances in Muller cells of fish. Glia 1:275-281.

Noble M (1988) Developmental biology of the optic nerve. In: Neural development and regeneration NATO-ASI Series, Vol 22: (Gorio A, Perez-Polo JR, de Vellis J, Haber B, eds), pp 4-19. Berlin: Springer Verlag.

Nona SN, Shehab SAS, Stafford CA, Cronly-Dillon JR (1989) Glial fibrillary acidic protein (GFAP) from goldfish: its localisation in the visual pathway. Glia 2:189-200.

Orkand RW, Nicholls JG, Kuffler SW (1966) Effect of nerve impulses on the membrane potential of glial cells in the central nervous system of amphibia. J Neurophysiol 36:788-806.

Overton J (1977) Formation of junctions and cell sorting in aggregates of mouse and chick cells. Dev Biol 55:103-116.

Owaribe K, Kartenbeck E, Rungger-Brändle E, and Franke WW (1988) Cytoskeletons of retinal pigment epithelial cells: interspecies differences in expression patterns indicate independence of cell function from the specific complement of cytoskeletal proteins. Cell Tissue Res 254:301-315.

Perry VH, Gordon S (1988) Macrophages and microglia in the nervous system. Trends Neurosci 11:273-277.

Pcrry VH, Hume DA, and Gordon S (1985) Immunohistochcmical localisation of macrophages and microglia in adult and developing mouse brain. Neuroscience 15:313-326.

Peters A, Palay SL, Webster H de F (1976) The fine structure of the nervous system. Philadelphia: WB Saunders.

Pitas RE, Boyles JK, Lee SH, Foss D, Mahley RW (1987) Astrocytes synthesise Apolipoprotein E and metabolise apolipoprotein E-containing lipoproteins. Biophys Biochem Acta 917:148-161.

Privat A (1975) Post-natal gliosis in the mammalian brain. Int Rev Cytol 40:281-323.

Quitschke W, Jones PS, Schechter N. (1985) Survey of intermediate filament proteins in the optic nerve and spinal cord. I Neurochem 44:1465-1476.

Quitschke W, Schechter N (1986) Homology and diversity between intermediate filament proteins of neuronal and non-neuronal origin in goldfish optic nerve. J Neurochem 46:545-555.

Raff MC (1989) Glial cell diversification in the rat optic nerve. Science 243:1450-1455.
Raff MC, Miller RH, Noble M (1983) A glial progenitor that develops in vitro into an astrocyte or an oligodendrocyte depending on culture medium. Nature 303:390-396.

Rakic P (1985) Contact regulation of neuronal migration. In: The cell in contact: adhesions and junctions as morphogenetic determinants (Edelman GM, Thiery J-P, eds), pp 67-81. New York: Neuroscience Research Foundation.

Ramón y Cajál, S (1955) Histologie du système nerveux de l'homme et des vertebrés, Instituto Ramón y Cajál, Madrid.

Richardson WD, Pringle N, Moseley MJ, Westermark B, Dubois-Dalca M (1988) A role for platelet-derived growth factor in normal gliogenesis in the central nervous system. Cell 53:309-319.

Roots BI (1986) Phylogenetic development of astrocytes. In: Astrocytes, Vol 1 (Fedoroff S, Vernadakis A, eds), pp 1-34. London: Academic Press.

Rovainen CM (1979) Neurobiology of lampreys. Physiol Rev 59: 1007-1077.

Rungger-Brändle E, Achtstatter T, Franke WW (1989) An epitheliumtype cytoskeleton in a glial cell: astrocytes of amphibian optic nerves contain cytokeratin filaments and are connected by desmosomes. J Cell Biol 109:705-716.

Schmechel DE, Rakic P (1979a) Arrested proliferation of radial glial cells during mid-gestation in rhesus monkey. Nature 277:303-305.

Schmechel DE, Rakic P (1979b) A Golgi study of radial glial cells in developing monkey telencephalon: morphogenesis and transformation into astrocytes. Anat Embryol 156:115-132.

Schnitzer J (1986) Distribution and immunoreactivity of glia in the retina of the rabbit. J Comp Neurol 240:128-142.

Schnitzer J (1988a) The development of astrocytes and blood vessels in the postnatal rabbit retina. J Neurocytol 17:433-449.

Schnitzer J (1988b) Astrocytes in the guinea-pig, horse and monkey retina: their occurrence coincides with the presence of blood vessels. Glia 1:74-89.

Scholes J (1979) Nerve fibre topography in the retinal projection to the tectum. Nature 278:620-624.

Schwartz M, Ernst SA, Siegel GJ, Agranoff BW (1981) Immunocytochemical localisation of $(\mathrm{Na}, \mathrm{K})$-ATPase in goldfish optic nerve. $J$ Neurochem 36:107-115.

Skoff RP (1980) Neuroglia: a re-evaluation of their origin and development. Pathol Res Pract 168:279-300.

Skoff RP, Price D, Stocks A (1976) Electron microscopic studies of gliogenesis in rat optic nerve: II. Time of origin. J Comp Neurol 169: 313-333.

Stensaas LJ, Stensaas SS (1968a) Astrocytic neuroglial cells, oligodendrocytes and microgliacytes in the spinal cord of the toad. I. Light microscopy. Z Zellforsch 84:473-489.

Stensaas LJ, Stensaas SS (1968b) Astrocytic neuroglial cells, oligodendrocytes and microgliacytes in the spinal cord of the toad: II. Electron microscopy. Z Zellforsch 86:184-213.

Stevenson JA, Yoon MG (1982) Morphology of radial glia, ependymal cells and periventricular neurons in the optic tectum of goldfish $(\mathrm{Ca}$ rassius auratus). J Comp Neurol 205:128-138.

Streit WI, Graeber MB, Kreutzberg GW (1988) Functional plasticity of microglia: a review. Glia 1:301-307.

Tang CM, Orkand PM, Orkand RK (1985) Coupling and uncoupling of amphibian neuroglia. Neurosci Lett 54:237-242.

Tapp RL (1974) Axon numbers and distribution, myelin thickness and the reconstruction of the compound action potential in the optic ncrve of the teleost Eugerres plumieri. J Comp Neurol 153:267-274.

Trewavas E (1983) Tilapiine fish of the genera Sarotherodon, Oreochromis and Danakilia. Dorchester, UK: British Museum/The Dorset Press.

Usowicz MM, Gallo V, Cull-Candy SG (1989) Multiple conductance channels in type- 2 cerebellar astrocytes activated by excitatory amino acids. Nature 339:380-383.

Vaughn JE (1969) An electron microscopic analysis of gliogenesis in the rat optic nerve. Z Zellforsch 94:293-324.

Virchow R (1867) Zur pathologischen Anatomie des Gehirns. 1. Congenitale Encephalitis und Myelitis. Virchow's Arch Pathol Anat 38: 129-138.

Wässle H, Riemann HJ (1978) The mosaic of nerve cells in the mammalian retina. Proc R Soc London [Biol] 200:441-461.

Waxman SG (1987) Rules governing membrane reorganisation and astroglial interactions during development of myelinated fibres. In: Prog. Brain Res., Vol 71: Neural regeneration (Seil FJ, Herbert E, Carlson BM, eds), pp 121-141. Amsterdam: Elsevier. 
Wilson MA (1971) Optic nerve fibre counts and retinal ganglion cell counts during development of Xenopus laevis. Q J Exp Physiol 56: 83-91.

Whitear M, Mittal AK, Lane EB (1980) Endothelial layers in fish skin. J Fish Biol 17:43-65.
Wolff JR (1987) The development of intracerebral blood vessels interacts with astrocyte development and neuron positioning in the rat neocortex. In: Mesenchymal-epithelial interactions in neural development (Wolff JR, Sievers K, Berry M, eds), pp 399-411. Berlin: Springer-Verlag. 